\title{
BMJ Open Scottish adolescents' sun-related behaviours, tanning attitudes and associations with skin cancer awareness: a cross-sectional study
}

\author{
Richard G Kyle, ${ }^{1}$ Iona MacMillan, ${ }^{2}$ Liz Forbat, ${ }^{1}$ Richard D Neal, ${ }^{3}$ \\ Ronan E O'Carroll, ${ }^{4}$ Sally Haw, ${ }^{5}$ Gill Hubbard ${ }^{1}$
}

To cite: Kyle RG,

MacMillan I, Forbat L, et al. Scottish adolescents' sunrelated behaviours, tanning attitudes and associations with skin cancer awareness: a cross-sectional study. BMJ Open 2014;4:e005137. doi:10.1136/bmjopen-2014005137

- Prepublication history for this paper is available online. To view these files please visit the journal online (http://dx.doi.org/10.1136/ bmjopen-2014-005137).

Received 26 February 2014 Revised 9 April 2014 Accepted 15 April 2014

CrossMark

For numbered affiliations see end of article.

Correspondence to Dr Richard G Kyle; richard.kyle@stir.ac.uk

\section{ABSTRACT}

Objectives: To describe Scottish adolescents' sunrelated behaviours and tanning attitudes and assess associations with skin cancer awareness.

Design: Cross-sectional study.

Setting: 20 state secondary schools in one Scottish local authority (Glasgow City).

Participants: 2173 adolescents (females: 50.7\%, $\mathrm{n}=1102)$ with a mean age of $12.4(\mathrm{SD}=0.55)$.

Outcome measures: Sun-related behaviour (suntan, sunbathing, sunburn, sunscreen use, sunbed use), tanning attitudes, skin cancer-related symptom and risk factor awareness.

Results: Adolescents reported poor sun-related practice: $51 \%$ of adolescents reported sunburn the previous summer of whom $38 \%$ indicated sunburn on more than one occasion. Skin cancer awareness was low: $45 \%$ recognised 'change in the appearance of a mole' as a cancer symptom, and $39 \%$ agreed that 'getting sunburnt more than once as a child' increased cancer risk. $42 \%$ and $26 \%$ of adolescents, respectively, reported that friends and family held protanning attitudes. Compared with males, females were statistically significantly more likely to: report sunbathing $(p<0.001)$, use of lotions or oil to aid tanning $(p=0.009)$ and sunburn $(p<0.001)$; know that changes in the appearance of a mole was a skin cancer symptom $(\mathrm{p}=0.036)$ and sunburn more than once as a child was a skin cancer risk factor $(p=0.005)$; perceive their friends to hold protanning attitudes $(p<0.001)$ and indicate that a tan made them feel better about themselves $(p<0.001)$, more attractive to others $(p=0.011)$ and healthier $(p<0.001)$.

Conclusions: Scottish adolescents had poor sun protection practice and low skin cancer awareness. Girls adopted riskier sun-related behaviour despite greater awareness of skin cancer-related risk. Urgent action is required to promote positive sun-related behaviour and increase skin cancer awareness among Scottish adolescents. However, further research is needed to inform the development of effective sunsafe interventions.

\section{Strengths and limitations of this study}

- This is the first study to describe Scottish adolescents' sun-related behaviours and tanning attitudes and assess associations with malignant melanoma symptom and risk factor awareness.

- Findings establish evidence to support ongoing government initiatives to increase the proportion of people with early diagnosis, including Detect Cancer Early (DCE) in Scotland and the National Awareness and Early Diagnosis Initiative (NAEDI) in England.

- Adolescents in only one Scottish local authority area were surveyed and non-probabilistic sampling was used, although Glasgow was purposefully selected due to known high incidence of malignant melanoma in the Central Belt of Scotland, a densely populated urban region extending from Glasgow in the west to Edinburgh in the east.

\section{INTRODUCTION}

Rates of malignant melanoma are rising more rapidly than for any other cancer in the UK ${ }^{1}$ and Scotland has above average incidence when compared with the rest of the $\mathrm{UK}^{2}$ Incidence of malignant melanoma in Scotland significantly increased by $51.4 \%$ $(\mathrm{p}<0.0001)$ over the past decade. ${ }^{3}$ Light skin colour, blonde or red hair, number of moles, ${ }^{4}$ family history ${ }^{5}$ and excess exposure to ultraviolet (UV) radiation, particularly in childhood, are the main risk factors for malignant melanoma. ${ }^{6}$ It is estimated that $86 \%$ of malignant melanoma cases in the UK can be attributable to excess exposure to UV radiation $($ male $=90 \%$, female $=82 \%)$, and that these proportions are "very much greater at younger ages'. ${ }^{7}$

Malignant melanoma is the fifth most common teenage and young adult cancer in 
the UK, accounting for $11 \%$ of the 2200 average annual cases among those aged $15-24 .^{8}$ Almost twice as many females $(n=153)$ than males $(n=73)$ are diagnosed with malignant melanoma annually, making it the third and sixth most common cancer in young women and men, respectively. ${ }^{8}$ Incidence of malignant melanoma significantly increased by $32 \%$ among young females between 1995 and 2009. ${ }^{8}$

Across the UK, survival rates for malignant melanoma are high and increasing over time, ${ }^{9}$ and in Scotland 5 -year survival rates rose by $21 \%$ over the past 20 years, from $64 \%$ in the period $1983-1997$ to $85 \%$ in $2003-$ $2007 .{ }^{10}$ Survival is higher in younger people ${ }^{10}$ and there is some evidence that longer time durations prior to diagnosis may be associated with poorer outcomes. ${ }^{11-13}$ UK government health departments are therefore committed to improving awareness as part of a strategy to increase the proportion of people with early diagnosis. ${ }^{14} 15$ Increasing adolescents' awareness of skin cancer risk associated with UV exposure and encouraging sun protective practices may therefore have potential to reduce the burden of malignant melanoma in adolescence and early adulthood, as well as in later life through the establishment of protective health-related behaviours. However, previous research has found that although adolescents' awareness of skin cancer and its association with UV exposure is generally good ${ }^{16} 17$ this knowledge does not translate into sun-safe behaviour, ${ }^{18} 19$ especially among young females. ${ }^{19-21}$

Little evidence exists around the association between sun-related behaviours and cancer awareness among adolescents in the UK. Only one UK study to date has examined the association between sunscreen and sunbed use and cancer awareness, which found that female adolescents who used sunbeds were statistically significantly more likely to agree that UV exposure was a cancer risk factor. ${ }^{21}$ Moreover, patterns of sun-related behaviours (ie, sunbathing and sunburn) and protective practices (ie, sunscreen use) and tanning attitudes among Scottish adolescents have not previously been described. This lack of evidence hampers development of interventions to increase cancer awareness and change sun-related behaviours in support of government initiatives. Hence, the aims of this study were to: (1) describe the sun-related behaviours and tanning attitudes among Scottish adolescents and (2) assess associations between sun-related behaviour, tanning attitudes and cancer awareness.

\section{METHODS}

\section{Study design}

Data are drawn from the Adolescent Cancer Education (ACE) study, the design of which is described in the published protocol. ${ }^{22}$ Briefly, ACE is a cluster randomised controlled trial (RCT) to assess the effectiveness of a school-based educational intervention on adolescents' and parents' cancer awareness and communication. Data were collected at three time points: baseline (prior to intervention delivery), and at 2 weeks, and 6-month follow-up. This paper reports cross-sectional analysis of baseline data.

\section{Setting and sample}

All 29 state secondary schools (excluding schools for adolescents with special educational needs) in the Glasgow City Council area were invited to participate. Recruitment ended when the (pragmatic) target of 20 schools $(69.0 \%)$ agreed to participate. All 3223 adolescents on the school register at the end of their first year (S1) of secondary education (age 12/13 years) in study schools were invited to participate in the study, of which $2173(67.4 \%)$ consented to data collection.

\section{Recruitment and consent}

Schools were recruited in May 2013 and adolescents in June 2013. School head teachers were contacted by letter, which was followed up with a telephone call and face-to-face meeting to invite participation in the study. Parents/carers were sent a letter and information sheet about the study, which included a form to be returned to school if they wished to opt their child out of the study. The opt-out method of parental consent has been found to be ethically acceptable. ${ }^{23}$ Adolescents were provided with an information sheet at the time measurements were undertaken and also asked to give written consent to their participation in the study.

\section{Survey instrument}

Data were collected in June 2013 (ie, northern hemisphere summer) using a self-complete paper questionnaire administered by teachers to a whole class under exam conditions but students were informed that it was not a test. Teachers encouraged students to complete as much of the questionnaire as they could within the 50 or 55 min lesson period.

The instrument incorporated validated questions on adolescents' sun-related behaviours and tanning attitudes ${ }^{19}$ the Cancer Awareness Measure (CAM),${ }^{24}{ }^{25}$ and sociodemographic questions.

\section{Sun-related behaviours and tanning attitudes}

Adolescents' tanning attitudes and sun-related behaviours were assessed using items from an instrument developed in New Zealand. ${ }^{19}$ Sun-related behaviours, including sunbathing, getting a suntan, use of sunbeds and sun protection practices during the previous summer (ie, 2012) or past 12 months were assessed through 10 questions. Attitudes towards tanning were assessed through five statements which used a five-point Likert scale to ask adolescents if a suntan made them 'feel healthier', 'more attractive to others' or 'better about themselves' and if friends and family thought that a suntan was a 'good thing'. For analysis, responses were dichotomised (ie, 'yes' vs 'no'; 'strongly agree'/'agree' vs 'neither agree nor disagree' /'disagree'/'strongly disagree'). 
Skin cancer symptom and risk factor awareness

Adolescents' awareness of skin cancer-related symptoms and risk factors were assessed through two questions in the CAM. Awareness of the cancer sign 'change in the appearance in a mole' was assessed alongside eight other cancer signs and symptoms through a recognition question. Awareness of the skin cancer-related risk factor 'getting sunburnt more than once as a child' was assessed alongside 10 other cancer risk factors on a five-point Likert scale. In accordance with previous practice, ${ }^{21} 25$ responses were dichotomised for analysis (ie, mole: 'yes' vs 'no'/'don't know'; sunburn: 'strongly agree'/'agree' vs 'not sure'/'disagree'/'strongly disagree').

\section{Sociodemographic characteristics}

Sociodemographic questions were included to gather data on: age, gender, ethnicity, and whether the student had been diagnosed or knew a relative or friend who had been diagnosed with any cancer.

\section{Data analysis}

Descriptive statistics were calculated for demographic variables (ie, age, gender, ethnicity, knowing someone with cancer), sun-related behaviours and tanning attitudes, and skin cancer-related symptom and risk factor awareness. Pearson's $\chi^{2}$ tests were used to assess associations between: (1) sun-related behaviours and gender; (2) tanning attitudes and gender and sun-related behaviour and (3) skin cancer-related symptom and risk factor awareness and gender, sun-related behaviours and tanning attitudes. Data were analysed using SPSS V.19.0. Significance tests were two-sided; $\mathrm{p}<0.05$ was considered statistically significant.

\section{Ethical considerations}

Glasgow City Council, Planning, Performance and Research Unit approved the involvement of secondary schools. All general practitioner practices in the research site were informed about the study.

\section{RESULTS \\ Sample}

The sample included 2173 (female: $\mathrm{n}=1102,50.7 \%$ ) adolescents with a mean age of $12.4(\mathrm{SD}=0.55)$ at the time of the survey. Sociodemographic characteristics of respondents are shown in table 1 .

\section{Sun-related behaviours}

\section{Suntan}

Around two-thirds (61.3\%, n=1333) of adolescents reported getting a suntan last summer. Slightly more girls than boys reported a suntan, although this difference was not statistically significant (girls: $66.2 \% \quad(\mathrm{n}=700)$, boys: $\left.63.4 \%(\mathrm{n}=616) ; \chi^{2}(1,2030)=1.73, \mathrm{p}=0.189\right)$.

\begin{tabular}{|c|c|c|}
\hline & $\mathbf{n}$ & Per cent \\
\hline \multicolumn{3}{|l|}{ Gender } \\
\hline Male & 1032 & 47.5 \\
\hline Female & 1102 & 50.7 \\
\hline Missing & 39 & 1.8 \\
\hline \multicolumn{3}{|l|}{ Age } \\
\hline Mean (SD) & 12.4 & $(0.55)$ \\
\hline \multicolumn{3}{|l|}{ Ethnicity } \\
\hline White & 1826 & 84.0 \\
\hline Mixed & 75 & 3.5 \\
\hline Asian & 131 & 6.0 \\
\hline Black & 57 & 2.6 \\
\hline Chinese & 15 & 0.7 \\
\hline Other & 28 & 1.3 \\
\hline Missing & 41 & 1.9 \\
\hline \multicolumn{3}{|c|}{ Knew someone with cancer } \\
\hline Yes & 1266 & 58.3 \\
\hline No & 783 & 36.0 \\
\hline Missing & 124 & 5.7 \\
\hline
\end{tabular}

\section{Sunbathing}

Four in ten (42.2\%, n=916) adolescents reported sunbathing regularly last summer to try to get a tan. Girls were statistically significantly more likely to report sunbathing (girls: $57.8 \%(\mathrm{n}=611)$, boys: $30.4 \% \quad(\mathrm{n}=294) ; \chi^{2}$ $(1,2025)=152.86, \mathrm{p}<0.001)$. Of those who sunbathed, $44.2 \% \quad(\mathrm{n}=405)$ reported using oils or lotions to aid tanning. Girls who sunbathed were statistically significantly more likely than boys to report using oils or lotions to help get a tan (girls: $47.4 \% \quad(\mathrm{n}=289)$, boys: $\left.38.1 \%(\mathrm{n}=111) ; \chi^{2}(1,901)=6.80, \mathrm{p}=0.009\right)$.

\section{Sunburn}

Half of adolescents $(51.2 \%, \mathrm{n}=1112)$ reported getting sunburnt last summer, of whom around two-thirds $(61.7 \%, \mathrm{n}=686)$ reported getting sunburnt on one occasion, and over a third $(38.3 \%, \mathrm{n}=426)$ reported getting sunburnt on more than one occasion. Girls were statistically significantly more likely to report getting sunburnt last summer (girls: $62.6 \% \quad(n=625)$, boys: $52.7 \% \quad(n=476)$; $\left.\chi^{2}(1,1902)=19.34, \mathrm{p}<0.001\right)$. Of the girls who reported getting sunburnt $(\mathrm{n}=625)$, almost 1 in $10(8.2 \%, \mathrm{n}=51)$ said that their 'skin went red, sore and blistered', nearly 4 in $10(39.0 \%, \mathrm{n}=244)$ said their 'skin went red and sore'; $24 \%(\mathrm{n}=150)$ reported their 'skin went red but not sore', and $27.7 \%$ ( $n=173)$ said their 'skin went pink or slightly red'. A greater proportion of boys than girls reported 'red, sore and blistered skin' $(11.3 \%, \mathrm{n}=54)$, although fewer reported that their 'skin went red and sore' $(34.2 \%, \mathrm{n}=163) ; 24.4 \% \quad(\mathrm{n}=116)$ reported their 'skin went red but not sore', and $27.9 \% \quad(n=133)$ said their 'skin went pink or slightly red'.

\section{Sunscreen use}

Nearly a fifth of adolescents $(16.8 \%, \mathrm{n}=365)$ reported that they 'did not usually use sunscreen'. Of those who 
reported using sunscreen $(74.0 \%, \mathrm{n}=1609)$, over half $(52.6 \%, \mathrm{n}=847)$ did not know the sun protection factor (SPF) of the sunscreen they usually used. The greatest proportion of adolescents who could identify the SPF of their sunscreen used SPF $>30(19.7 \%, \mathrm{n}=317)$, followed by: SPF30 $(15.2 \%, \mathrm{n}=244), \operatorname{SPF} 15(8.0 \%, \mathrm{n}=129)$ and $\mathrm{SPF}<15(4.5 \%, \mathrm{n}=72)$.

Of those who reported getting sunburnt $(51.2 \%$, $\mathrm{n}=1112), 1$ in $10(11.6 \%, \mathrm{n}=129)$ reported that they did not use sunscreen. Boys who got sunburnt were statistically significantly more likely to report not using sunscreen, with over 1 in 4 reporting that they did not use sunscreen (boys: $27.9 \% \quad(\mathrm{n}=72)$, girls: $15.4 \% \quad(\mathrm{n}=57) ; \chi^{2}$ $(1,629)=14.69, \mathrm{p}<0.001)$.

\section{Sunbed use}

One in $20(5.8 \%, \mathrm{n}=127)$ adolescents reported using a sunbed in the past 12 months. There was no statistically significant gender difference in sunbed use (girls: $6.3 \%$ $(\mathrm{n}=66)$, boys: $\left.6.3 \%(\mathrm{n}=59) ; \chi^{2}(1,1980)=0.003, \mathrm{p}=0.959\right)$.

\section{Tanning attitudes}

Peers exerted the greatest influence on adolescents' attitudes towards tanning with two-fifths $(42.3 \%, \mathrm{n}=918)$ stating that they strongly agreed or agreed with the statement "most of my friends think a suntan is a good thing." A quarter of adolescents $(26.1 \%, \mathrm{n}=567)$ agreed that their family thought a suntan was a good thing. A fifth of adolescents agreed that a suntan made them feel better about themselves $(22.7 \%, \mathrm{n}=492)$ and that a suntan made them feel more attractive to others $(18.8 \%$, $\mathrm{n}=409)$. A tenth $(12.3 \%, \mathrm{n}=267)$ agreed that they liked to have a suntan because it made them feel healthier. Gender differences were investigated and are summarised in table 2.

Adolescents of both sexes who reported sunbathing were statistically significantly more likely to agree with each of the five tanning attitude statements than those who did not report sunbathing (table 3). Boys who reported using sunbeds were statistically significantly more likely to agree with four of the five statements, the exception being the statement "most of my friends think a suntan is a good thing" for which there was no difference between boys who did and did not report sunbed use (table 3 ).

\section{Sun-related behaviour and cancer awareness Symptom awareness}

Less than half $(45.2 \%, \mathrm{n}=982)$ of adolescents thought that change in the appearance of a mole could be a sign of cancer. Girls were statistically significantly more likely to recognise that a change in the appearance of a mole was potentially a sign of cancer (girls: $48.0 \% \quad(n=524)$, boys: $\left.43.5 \%(\mathrm{n}=444) ; \chi^{2}(1,2112)=4.38, \mathrm{p}=0.036\right)$.

The only statistically significant association between symptom awareness and sun-related behaviour was among females who reported getting sunburnt, who were more likely to agree that a change in the appearance of a mole was potentially a sign of cancer (table 4).

\section{Risk factor awareness}

Four in $10(39.1 \%, \mathrm{n}=849)$ adolescents thought that getting sunburnt more than once as a child was a risk factor of cancer. Girls were statistically significantly more likely to agree that getting sunburnt more than once as a child was a cancer risk factor (girls: $43.4 \% \quad(n=469)$, boys: $\left.37.3 \%(\mathrm{n}=370) ; \chi^{2}(1,2071)=7.95, \mathrm{p}=0.005\right)$.

There were no statistically significant associations between awareness of getting sunburnt more than once as a child and sun-related behaviours, although adolescents of both sexes who reported getting sunburnt were more likely to agree that sunburn was a cancer risk factor (table 4).

\section{DISCUSSION}

Scottish adolescents' awareness of the symptoms and risk factors associated with skin cancer was low: less than half of adolescents identified 'change in the appearance of a mole' as a sign of cancer and fewer than $40 \%$ agreed that 'getting sunburnt more than once as a child'

\begin{tabular}{|c|c|c|c|}
\hline $\begin{array}{l}\text { Statement } \\
\text { Percentage of strongly agree/agree (n) }\end{array}$ & Female & Male & Significance* \\
\hline Most of my friends think a suntan is a good thing & $53.1(554)$ & $37.7(355)$ & $\begin{array}{l}\chi^{2}(1,1985)=47.48 \\
p<0.001\end{array}$ \\
\hline Most of my family thinks a suntan is a good thing & $29.0(301)$ & $27.8(260)$ & $\begin{array}{l}\chi^{2}(1,1974)=0.36 \\
p=0.548\end{array}$ \\
\hline I like to have a suntan because it makes me feel better about myself & $30.8(320)$ & $18.0(169)$ & $\begin{array}{l}\chi^{2}(1,1978)=43.10 \\
p<0.001\end{array}$ \\
\hline A suntan makes me feel more attractive to others & $22.7(235)$ & $18.1(169)$ & $\begin{array}{l}\chi^{2}(1,1969)=6.40 \\
p=0.011\end{array}$ \\
\hline I like to have a suntan because I feel healthier & $16.2(169)$ & $10.1(95)$ & $\begin{array}{l}\chi^{2}(1,1980)=15.99 \\
p<0.001\end{array}$ \\
\hline
\end{tabular}


Table 3 Tanning attitudes and sun-related behaviour

\begin{tabular}{|c|c|c|c|c|c|c|c|c|c|}
\hline \multirow{2}{*}{$\begin{array}{l}\text { Statement } \\
\text { Percentage of strongly } \\
\text { agree/agree (n) }\end{array}$} & \multicolumn{3}{|l|}{ Sunbathed } & \multicolumn{3}{|l|}{ Sunburnt } & \multicolumn{3}{|c|}{ Sunbed use } \\
\hline & Yes & No & Significance* $^{\star}$ & Yes & No & Significance* $^{\star}$ & Yes & No & Significance* $^{\star}$ \\
\hline \multicolumn{10}{|l|}{ Female } \\
\hline $\begin{array}{l}\text { Most of my friends think a suntan } \\
\text { is a good thing }\end{array}$ & $61.8(371)$ & $40.6(177)$ & $\begin{array}{l}\chi^{2}(1,1036)=45.71 \\
p<0.001\end{array}$ & $60.1(370)$ & $42.7(157)$ & $\begin{array}{l}\chi^{2}(1,984)=28.05 \\
p<0.001\end{array}$ & $62.1(41)$ & $52.1(500)$ & $\begin{array}{l}\chi^{2}(1,1026)=2.50 \\
p=0.114\end{array}$ \\
\hline $\begin{array}{l}\text { Most of my family thinks a suntan } \\
\text { is a good thing }\end{array}$ & 35.7 (214) & $19.9(86)$ & $\begin{array}{l}\chi^{2}(1,1031)=30.44 \\
p<0.001\end{array}$ & $31.1(191)$ & $25.6(94)$ & $\begin{array}{l}\chi^{2}(1,982)=3.31 \\
p=0.069\end{array}$ & $39.1(25)$ & $28.1(269)$ & $\begin{array}{l}\chi^{2}(1,1021)=3.51 \\
p=0.061\end{array}$ \\
\hline $\begin{array}{l}\text { I like to have a suntan because it } \\
\text { makes me feel better about } \\
\text { myself }\end{array}$ & $42.6(255)$ & $14.5(63)$ & $\begin{array}{l}\chi^{2}(1,1032)=93.32 \\
p<0.001\end{array}$ & $38.0(234)$ & $20.6(75)$ & $\begin{array}{l}\chi^{2}(1,980)=32.02 \\
p<0.001\end{array}$ & $33.3(22)$ & $30.4(291)$ & $\begin{array}{l}\chi^{2}(1,1022)=0.24 \\
p=0.622\end{array}$ \\
\hline $\begin{array}{l}\text { A suntan makes me feel more } \\
\text { attractive to others }\end{array}$ & $31.3(187)$ & $10.9(47)$ & $\begin{array}{l}\chi^{2}(1,1029)=59.62 \\
p<0.001\end{array}$ & $26.6(163)$ & $16.4(60)$ & $\begin{array}{l}\chi^{2}(1,979)=13.55 \\
p<0.001\end{array}$ & $26.2(17)$ & $22.4(213)$ & $\begin{array}{l}\chi^{2}(1,1018)=0.50 \\
p=0.478\end{array}$ \\
\hline $\begin{array}{l}\text { I like to have a suntan because I } \\
\text { feel healthier }\end{array}$ & $23.2(139)$ & $6.9(30)$ & $\begin{array}{l}\chi^{2}(1,1035)=48.86 \\
p<0.001\end{array}$ & $18.0(111)$ & $12.4(46)$ & $\begin{array}{l}\chi^{2}(1,986)=5.40 \\
p=0.020\end{array}$ & $19.7(13)$ & $15.6(150)$ & $\begin{array}{l}\chi^{2}(1,1025)=0.76 \\
p=0.383\end{array}$ \\
\hline \multicolumn{10}{|l|}{ Male } \\
\hline $\begin{array}{l}\text { Most of my friends think a suntan } \\
\text { is a good thing }\end{array}$ & $54.8(154)$ & $30.3(197)$ & $\begin{array}{l}\chi^{2}(1,932)=50.36 \\
p<0.001\end{array}$ & $41.9(195)$ & $34.5(143)$ & $\begin{array}{l}\chi^{2}(1,880)=5.18 \\
p=0.023\end{array}$ & $37.9(22)$ & $38.0(325)$ & $\begin{array}{l}\chi^{2}(1,914)=0.00 \\
p=0.996\end{array}$ \\
\hline $\begin{array}{l}\text { Most of my family thinks a suntan } \\
\text { is a good thing }\end{array}$ & $43.5(121)$ & $21.1(137)$ & $\begin{array}{l}\chi^{2}(1,926)=48.49 \\
p<0.001\end{array}$ & $30.3(139)$ & $25.2(104)$ & $\begin{array}{l}\chi^{2}(1,876)=2.55 \\
p=0.110\end{array}$ & 39.7 (23) & $26.4(225)$ & $\begin{array}{l}\chi^{2}(1,909)=4.78 \\
p=0.029\end{array}$ \\
\hline $\begin{array}{l}\text { I like to have a suntan because it } \\
\text { makes me feel better about } \\
\text { myself }\end{array}$ & $32.9(91)$ & $11.7(76)$ & $\begin{array}{l}\chi^{2}(1,928)=59.06 \\
p<0.001\end{array}$ & $21.6(100)$ & 13.8 (57) & $\begin{array}{l}\chi^{2}(1,876)=9.02 \\
p=0.003\end{array}$ & $29.3(17)$ & $17.0(145)$ & $\begin{array}{l}\chi^{2}(1,911)=5.63 \\
p=0.018\end{array}$ \\
\hline $\begin{array}{l}\text { A suntan makes me feel more } \\
\text { attractive to others }\end{array}$ & 32.1 (88) & 12.2 (79) & $\begin{array}{l}\chi^{2}(1,924)=51.88 \\
p<0.001\end{array}$ & $20.0(93)$ & $15.9(66)$ & $\begin{array}{l}\chi^{2}(1,880)=2.59 \\
p=0.108\end{array}$ & 30.9 (17) & $17.1(145)$ & $\begin{array}{l}\chi^{2}(1,905)=6.74 \\
p=0.009\end{array}$ \\
\hline $\begin{array}{l}\text { I like to have a suntan because I } \\
\text { feel healthier }\end{array}$ & $19.8(54)$ & $5.8(38)$ & $\begin{array}{l}\chi^{2}(1,928)=42.16 \\
p<0.001\end{array}$ & $12.0(56)$ & $7.2(30)$ & $\begin{array}{l}\chi^{2}(1,884)=5.88 \\
p=0.015\end{array}$ & $25.0(14)$ & $9.0(77)$ & $\begin{array}{l}\chi^{2}(1,926)=14.88 \\
p<0.001\end{array}$ \\
\hline
\end{tabular}




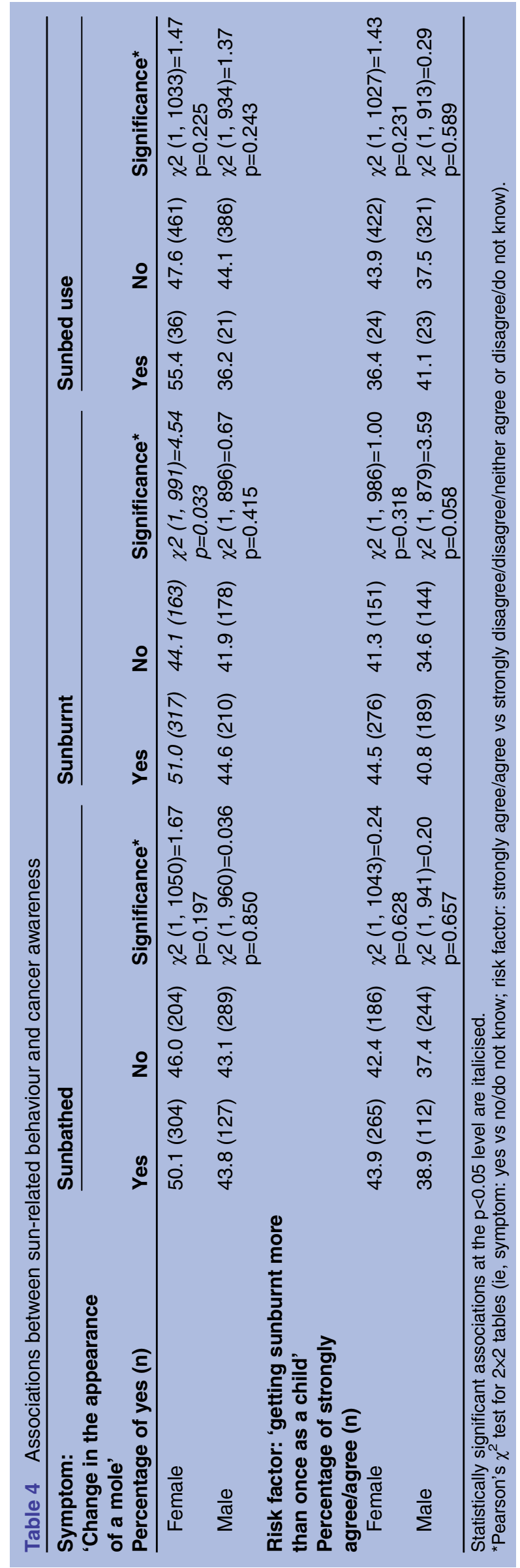

increased cancer risk. This confirms findings from an earlier small-scale UK study ${ }^{21}$ and suggests that awareness of skin cancer symptoms and risks among Scottish adolescents compares unfavourably with adolescents elsewhere in Europe. For example, the majority $(97 \%)$ of Italian secondary school students (aged 15-21 years) had heard of skin cancer and $66 \%$ and $59 \%$, respectively, correctly identified sun exposure and sunburn as skin cancer risk factors. ${ }^{16}$ Similarly, a study of Greek adolescents (aged $15-18$ years) found that $89 \%$ were aware of the association between sun exposure and skin cancer risk. ${ }^{17}$

Adolescents also reported poor sun protection practices with half $(51 \%)$ reporting that they had experienced sunburn last summer. Over a third $(38 \%)$ of those reporting sunburn experienced sunburn on more than one occasion and a 10th (10\%) said that their skin went 'red, sore or blistered'. Sunscreen use was also notably poor with almost a fifth of adolescents reporting that they did not use sunscreen and less than half (47\%) of those who did knew the SPF of the sunscreen used. Given the causal relationship between UV exposure and incidence of malignant melanoma, ${ }^{7}$ our findings suggest that urgent action is required to reduce levels of sunburn among Scottish adolescents in order to reverse rising rates of malignant melanoma.

In common with previous studies from the UK, ${ }^{21}$ USA, ${ }^{18}$ Sweden ${ }^{20}$ and New Zealand, ${ }^{19}$ our research also identified riskier sun-related behaviour among female adolescents despite their greater skin cancer symptom and risk factor awareness. Females in our study were significantly more likely than males to report intentional tanning, the use of lotions or oils to aid tanning and sunburn, yet were also significantly more likely to agree that 'change in the appearance of a mole' was a cancer sign and 'getting sunburnt more than once as a child' was a cancer risk factor. Indeed, females who reported getting sunburnt during the previous summer were statistically significantly more likely to recognise that 'change in the appearance of a mole' was a cancer sign. However, compared with males, females were also significantly more likely to use sunscreen, confirming findings of a systematic review that concluded that females were more likely to adopt sun-protection practices and more likely to engage in risky sun-related behaviours, and that this association was most evident in adolescence and early adulthood. ${ }^{26}$ Cognitive dissonance, denial and previous personal or vicarious experience have all been identified as pivotal factors in the relationship between adolescents' risk perception and risk behaviour. ${ }^{27}$ Hence, health promotion in relation to sun-safe practices needs to be underpinned by greater understanding of how adolescents balance harms and perceived benefits of tanning.

External influences of friends and family exerted a stronger influence on tanning attitudes than associations with feeling better, more attractive or healthier. More than two-fifths agreed that most of their friends thought that a tan was a good thing, yet around a fifth said it 
made them feel better and more attractive and around a 10th that it made them feel healthier. The primacy of peer influences has also been found among similarly aged adolescents in Australasia. For example, a study in New Zealand found that $42 \%$ of females and $33 \%$ of males agreed that 'most of their friends think a suntan is a good thing, ${ }^{19}$ and the majority $(66 \%)$ of adolescents in an Australian study perceived friends to have protanning attitudes. ${ }^{28}$ Moreover, there is evidence from a Danish study that sunburn risk increases among adolescents (aged 13-17 years) whose parents hold positive attitudes towards tanning, ${ }^{29}$ and the highest ranking source of sun protection information among young park-goers in London (aged 18-28 years) was 'parents and family'. ${ }^{30}$ Further research is therefore required to assess peer and family influences on Scottish adolescents' tanning attitudes in order to determine the potential of peer-group and family-based interventions to reduce risky sun-related behaviours.

Females in our study were statistically significantly more likely than males to report that their friends think a suntan is a good thing and that it made them feel better about themselves, healthier or more attractive to others. Tanning attitudes mediate the association between skin cancer knowledge and sun-related behaviour, ${ }^{19} 31$ and more positive attitudes towards tanning among females are cosmetically and socially motivated. ${ }^{20}$ Moreover, the influence of peers on tanning attitudes is known to increase as adolescents age. ${ }^{19}$ In order to design age-appropriate sun safety interventions, further research is therefore required to better understand how the balance between social, cosmetic and health motivations changes over time, especially among young females.

\section{Implications for future policy and research}

Our research identifies an urgent need to develop sun safety interventions specifically for Scottish adolescents. However, our study also suggests that further research is required to ensure interventions overcome a number of challenges previously highlighted in the literature and confirmed by our own research. Research is required to assess how skin cancer knowledge, sun-related behaviour and tanning attitudes-and the influence of peers and family on knowledge, behaviour and attitudes-change as adolescents' age. Testing behaviour change techniques $^{32}$ which show promise such as those based on dissonance ${ }^{33} 34$ to address the known discordance between sun protection intention and practice ${ }^{30} 35$ would also be useful. This research is vital because previous interventions to change sun-safe knowledge and practice have been disappointing ${ }^{36}$ and it is not known which educational techniques are most effective. ${ }^{37}$ Despite considerable challenges of effective intervention development for this age group, previous research has found that school-based educational interventions to raise adolescents' cancer awareness are effective, ${ }^{38}$ especially among females. ${ }^{21}{ }^{39}$ Hence, multicomponent interventions that incorporate education alongside challenges to societal beliefs around tanning (eg, the association between tanned skin, beauty and health) and environmental changes (eg, provision of sunscreen, hats and shade in secondary schools) may encourage protective sun-related behaviours. Future research identified in support of intervention development has potential to have international impact on reducing the burden of skin cancer.

\section{Strengths and limitations}

This is the first study to describe Scottish adolescents' sun-related behaviours and tanning attitudes and assess associations with cancer awareness. It establishes an evidence base to set the direction of future research and policy interventions through ongoing initiatives such as Detect Cancer Early in Scotland and the National Awareness and Early Diagnosis Initiative (NAEDI) in England. However, our study has a number of limitations. First, our sample is drawn from only one Scottish local authority area (Glasgow City Council) and used purposive rather than probabilistic sampling. Thus, although 2173 adolescents from 20 (of a possible 29) secondary schools in Glasgow were surveyed, these findings may not be representative of the Scottish adolescent population. However, Glasgow was purposefully selected as a research site due to known high incidence of malignant melanoma in the Central Belt of Scotland, a densely populated urban region extending from Glasgow in the west to Edinburgh in the east. ${ }^{2}$ Second, although validated instruments were used for data collection, results are contingent on adolescents' accurate recall of sun-related behaviour during summer 2012, around 9-12 months previously. Previous studies among adolescents have found recall of sun-related behaviours to be reliable and valid ${ }^{31}$; although the possibility that recall bias influences our findings cannot be discounted due to the length of time since the previous summer (eg, reporting of less severe sunburn, frequency of sunburn or SPF of sunscreen used may be particularly prone to bias). Finally, because data were gathered as part of a cluster RCT, ${ }^{22}$ in order to enable completion of all instruments during a $55 \mathrm{~min}$ class, a shortened version of an instrument to assess sun-related knowledge, behaviour and tanning attitudes ${ }^{19}$ was used which meant that replication of analysis conducted elsewhere using the full instrument could not be conducted. ${ }^{19}$ Future research is therefore required using a representative sample of Scottish adolescents using the full version of the sun instrument with additional items to gather data on known skin cancer risk factors to enable such analyses and more comprehensive comparison with studies of similarly aged secondary school students in New Zealand ${ }^{19}$ and Australia ${ }^{28}$ where this instrument has been used.

\section{Conclusion}

Scottish adolescents' awareness of skin cancer symptoms and risk factors was low and matched by poor sun 
protection behaviours, most apparent in the high prevalence of (often severe) sunburn during the previous summer. These findings suggest that if the continuing rise in incidence of malignant melanoma in Scotland is to be halted, urgent action is required to increase skin cancer awareness and promote positive sun-related behaviour among Scottish adolescents. Our study highlights that the relationship between risk knowledge and risk behaviour is complex and different for adolescent males and females. Thus, further research is needed to inform the development of effective sun-safe interventions.

\section{Author affiliations}

${ }^{1}$ Cancer Care Research Centre, School of Nursing, Midwifery and Health, University of Stirling, Stirling, UK

${ }^{2}$ Teenage Cancer Trust, London, UK

${ }^{3}$ North Wales Centre for Primary Care Research, Bangor University, Bangor UK

${ }^{4}$ Division of Psychology, School of Natural Sciences, University of Stirling, Stirling, UK

${ }^{5}$ School of Nursing, Midwifery and Health, University of Stirling, Stirling, UK

Acknowledgements The authors are grateful to the adolescents who completed questionnaires, and the parents, schools and teachers who supported this work

Contributors RGK designed and conducted data analysis. IM and GH managed school and participant recruitment and data collection. RGK and GH wrote the first draft of the paper, and LF, RDN, REO'C and SH provided critical revision for important intellectual content. All authors read and approved the final manuscript.

Funding This work was supported by Teenage Cancer Trust and the Scottish Government Detect Cancer Early Programme. The views expressed in this paper are not necessarily those of Teenage Cancer Trust or the Scottish Government. RDN receives funding from Public Health Wales and Betsi Cadwaladr University Health Board.

Competing interests IM is employed by Teenage Cancer Trust. GH secured funding and ethical approval.

Ethics approval School Research Ethics Committee (SREC), School of Nursing, Midwifery and Health, University of Stirling (reference: 13/14(83))

Provenance and peer review Not commissioned; externally peer reviewed.

Data sharing statement Data collected using the Cancer Awareness Measure (CAM) for the purposes of this study will be available through the UK Data Archive in accordance with the conditions of use of the CAM.

Open Access This is an Open Access article distributed in accordance with the Creative Commons Attribution Non Commercial (CC BY-NC 3.0) license, which permits others to distribute, remix, adapt, build upon this work noncommercially, and license their derivative works on different terms, provided the original work is properly cited and the use is non-commercial. See: http:// creativecommons.org/licenses/by-nc/3.0/

\section{REFERENCES}

1. Thomson CS, Woolnough S, Wickenden M, et al. Sunbed use in children aged 11-17 in England: face to face quota sampling surveys in the National prevalence Study and Six Cities study. BMJ 2010;340:c877.

2. Quinn M, Wood H, Cooper N, et al. Cancer Atlas of the United Kingdom and Ireland 1991-2000. Studies on medical and population subjects No. 68. London: Office for National Statistics, 2005.

3. Information Services Division (iSD). 2013 Cancer incidence in Scotland. Edinburgh: iSD, 2011.
4. Gandini S, Sera F, Cattaruzza MS, et al. Meta-analysis of risk factors for cutaneous melanoma: I. Common and atypical naevi. Eur J Cancer 2005;41:28-44.

5. Gandini S, Sera F, Cattaruzza MS, et al. Meta-analysis of risk factors for cutaneous melanoma: III. Family history, actinic damage and phenotypic factors. Eur J Cancer 2005;41:2040-59.

6. Gandini S, Sera F, Cattaruzza MS, et al. Meta-analysis of risk factors for cutaneous melanoma: II. Sun exposure. Eur J Cancer 2005;41:45-60.

7. Parkin DM, Mesher D, Sasieni P. Cancer attributable to solar (ultraviolet) radiation exposure in the UK in 2010. Br J Cancer 2011;105:S66-9.

8. Cancer Research UK (CRUK). Teenage and young adult cancer incidence statistics. 2013. http://www.cancerresearchuk.org/ cancer-info/cancerstats/teenage-and-young-adult-cancer/

9. Cancer Research UK (CRUK). Skin cancer survival statistics. 2013. http://www.cancerresearchuk.org/cancer-info/cancerstats/types/skin/ survival/\#source6

10. Information Services Division (iSD). Trends in cancer survival in Scotland, 1983-2007. Edinburgh: iSD, 2010.

11. Betti RR, Vergani R, Tolomio E, et al. Factors of delay in the diagnosis of melanoma. Eur J Dermatol 2003;13:183-8.

12. Krige JE, Isaacs $\mathrm{S}$, Hudson DA, et al. Delay in the diagnosis of cutaneous malignant melanoma. A prospective study in 250 patients. Cancer 1991;68:2064-8.

13. Richard MA, Grob JJ, Avril MF, et al. Melanoma and tumor thickness: challenges of early diagnosis. Arch Dermatol 1999;135:269-74.

14. Department of Health (DH). Cancer reform strategy. London: DH, 2007.

15. Scottish Government. Detect cancer early initiative: draft plan. Edinburgh: Scottish Government, 2011.

16. Suppa M, Cazzaniga S, Fargnoli MC, et al. Knowledge, perceptions and behaviours about skin cancer and sun protection among secondary school students from Central Italy. J Eur Acad Dermatol Venereol 2013;27:571-9.

17. Saridi M, Toska A, Pappa V, et al. Knowledge, attitudes and self care practices related to sun protection among teenagers in Greece. Arch Hellenic Med 2009;26:355-65.

18. Knight JM, Kirincich AN, Farmer ER, et al. Awareness of the risks of tanning lamps does not influence behaviour among college students. Arch Dermatol 2002;138:1311-15.

19. Wright $\mathrm{C}$, Reeder Al, Gray A, et al. Child sun protection: sun-related attitudes mediate the association between children's knowledge and behaviours. J Pediatr Child Health 2008;44:692-8.

20. Sjöberg, Holm LE, Ullen $\mathrm{H}$, et al. Tanning and risk perception in adolescents. Health Risk Soc 2004;6:81-94.

21. Kyle RG, Nicoll A, Forbat L, et al. Adolescents' awareness of cancer risk factors and associations with health-related behaviours. Health Educ Res 2013;28:816-27.

22. Kyle RG, Macmillan I, Rauchhaus $P$, et al. Adolescent Cancer Education (ACE) to increase adolescent and parent cancer awareness and communication: study protocol for a cluster randomised controlled trial. Trials 2013;14:286.

23. Economic and Social Research Council (ESRC). ESRC framework for research ethics. Swindon: ESRC, 2010.

24. Cancer Research UK. Cancer Awareness Measure Toolkit V2.1. London: Cancer Research UK, 2011.

25. Kyle RG, Forbat L, Hubbard G. Cancer awareness among adolescents in Britain: a cross-sectional study. BMC Public Health 2012;12:580.

26. Kasparian NA, McLoone JK, Meiser B. Skin cancer-related prevention and screening behaviours: a review of the literature. $J$ Behav Med 2009;32:406-28.

27. Larsman $\mathrm{P}$, Eklof M, Torner M. Adolescents' risk perceptions in relation to risk behaviour with long-term health consequences; antecedents and outcomes: a literature review. Saf $\mathrm{Sci}$ 2012;50:1740-8.

28. Volkov A, Dobbinson S, Wakefield M, et al. Seven-year trends in sun protection and sunburn among Australian adolescents and adults. Aust N Z J Public Health 2013;37:63-9.

29. Behrens CL, Thorgaard C, Philip A, et al. Sunburn in children and adolescents: associations with parents' behaviour and attitudes. Scand J Public Health 2013;41:302-10.

30. Hedges T, Scriven A. Young park users' attitudes and behaviour to sun protection. Glob Health Promot 2010;17:24-31.

31. Andreeva VA, Reynolds KD, Buller DB, et al. Concurrent psychosocial predictors of sun safety among middle school youth. $J$ Sch Health 2008;78:374-81.

32. Michie S, Richardson $\mathrm{M}$, Johnston $\mathrm{M}$, et al. The behaviour change taxonomy (v1) of 93 hierarchically clustered techniques: building an international consensus for the reporting of behaviour change interventions. Ann Behav Med 2013;46:81-95. 
33. Freijy T, Kothe EJ. Dissonance-based interventions for health behaviour change: a systematic review. Br J Health Psychol 2013;18:310-37.

34. Stone J, Fernandez NC. When thinking about less failure causes more dissonance: the effect of elaboration and recall on behaviour change following hypocrisy. Soc Influence 2011;6:199-211.

35. Dobbinson SJ, Jamsen K, Dixon HG, et al. Assessing population-wide behaviour change: concordance of 10-year trends in self-reported and observed sun protection. Int J Public Health 2014;59:157-66.

36. Craciun C, Schuz N, Lippke S, et al. Enhancing planning stages for sunscreen use at different stages of change. Health Educ Res 2012;27:857-67.
37. Bellamy R. A systematic review of educational interventions for promoting sun protection knowledge, attitudes and behaviour following the QUESTS approach. Med Teach 2005;27: 269-75.

38. Saraiya M, Glanz K, Briss PA, et al. Interventions to prevent skin cancer by reducing exposure to ultraviolet radiation: a systematic review. Am J Prev Med 2004;27:422-6.

39. Kyle RG, Forbat L, Rauchhaus $P$, et al. Increased cancer awareness among British adolescents after a school-based educational intervention: a controlled before-and-after study with 6-month follow-up. BMC Public Health 2013;13:190. 